\title{
OPINION
}

Ayesh K Seneviratne, MSc ${ }^{1,2}$

Siraj K Zahr, PhD ${ }^{1,2}$

Sara Mirali, MSc ${ }^{1,2}$

Sachin Doshi, BSc ${ }^{1,2}$

Tina Binesh Marvasti, MSc ${ }^{1,2}$

Robert Civitarese, MSc ${ }^{1,2}$

Norman D Rosenblum, MD FRCPC2,3

${ }^{1}$ Apollo Society-Toronto Chapter, University of Toronto, Toronto, ON

2 Faculty of Medicine, University of Toronto, Toronto, ON

${ }^{3}$ Hospital for Sick Children, Toronto, ON

\section{Addressing the need for a new generation of young translational researchers that focuses on societal impact: The Apollo Toronto Story}

Manuscript submitted 7th August, 2019

Manuscript accepted 28th August, 2019

Clin Invest Med 2019; 42 (3): E14-16.

\begin{abstract}
Translational research (TR) is a multidirectional and multidisciplinary integration of basic research, patient-oriented research and population-based research, with the long-term goal of improving human health. Unfortunately, the current scientific training system does not adequately align with the goals of TR. To address this issue, an organization called Apollo Toronto was established at the University of Toronto in Toronto, Ontario. Apollo Toronto is a medical student-run international collaborative project between the Eureka Institute for Translational Medicine and the University of Toronto (one of Eureka Institute's partner universities), and provides a general overview of TR to interested medical and graduate students. Through local and international initiatives, the various Apollo chapters (including Apollo Toronto) aim to establish a network of trainees equipped to address systemic issues that impede the translation of an ever-growing body of scientific literature into health solutions.
\end{abstract}

Correspondence to:

Dr. Siraj K Zahr

Email: siraj.zahr@mail.utoronto.ca 
Translational research (TR) is a multidirectional and multidisciplinary integration of basic research, patientoriented research, and population-based research, with the long-term aim of improving human health [1]. To conceptualize the changes and improvements in human health, the "9P-3P framework" can be used (Figure 1) [2]. The nine "Ps" are as follows: protecting health; promoting health; prolonging healthy life span; predicting diseases; prewarning of diseases; preventing diseases; population policy; patient participation in health decisions; and personalized medicine (Figure 1) [2]. Among these, prolonging healthy life span, preventing disease and personalizing medicine are the most important and are referred to as the three "Ps" of medicine [2]. An effective health solution is one that improves at least one of the health processes within the 9P-3P framework. The development of a health solution by following the TR process requires the following: 1) an understanding of TR components and the ability to articulate a health need with precision; 2) the ability to design a robust and tractable methodology to identify potential health solutions for further development; and 3) the ability

FIGURE 1. The "9P-3P" framework in human health. The nine Ps in medicine are used to conceptualize the improvement required in health care. Prolonging healthy life span, preventing disease and personalizing medicine are the most important and are referred to as the three "Ps" of medicine (shown in blue).

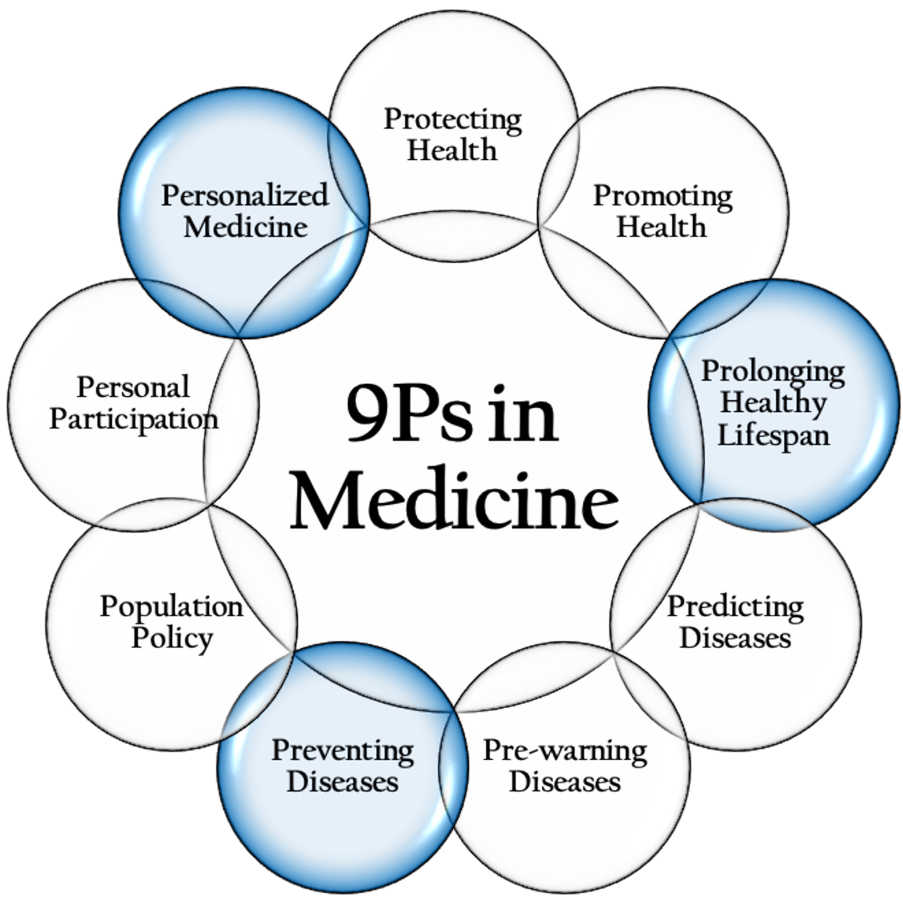

to conceptualize a method to assess the safety and efficacy of the proposed new intervention. Although it is impossible for a translational researcher to be an expert in all components that encompass TR, a broad conceptual understanding is required for success [1].

Unfortunately, the current scientific training system does not adequately align with the goals of TR. Incentives such as securing funds, jobs, promotions or tenure are primarily contingent upon a researcher's high publication output in high-impact journals [3,4]; however, there is no guarantee that a publication in a higher-impact journal is more likely to lead to a health solution compared with a study published in a lower impact journal [5,6]. These incentives have shaped the current scientific training goals and structure. Young investigators are primarily trained to publish, but rarely taught about the TR pipeline and the method to effectively translate knowledge generated in the laboratory to health solutions. There is a dire need for a system that teaches budding researchers the skills necessary to conceptualize, initiate and work on TR projects. Even upcoming basic science researchers who aspire to focus on discovery stand to benefit from this knowledge, by learning about the collaborations necessary to translate promising findings.

To address this gap in TR, several academic institutions across Canada have implemented training programs focused specifically on TR. University of Toronto and Queen's University (Kingston, Ontario) now offer professional graduate degrees in TR; however, interest in these programs far outweighs the number of available spots. Additionally, integrating the program effectively into a combined MD/ MSc degree has proven difficult given the logistical and academic constraints. Thus, while these programs are important means of educating individuals about TR concepts, their outreach is limited. To address this issue, Apollo Toronto was established.

Apollo Toronto is a chapter of Apollo, an international collaborative project between the Eureka Institute for Translational Medicine and its partner universities. Other Apollo chapters are located in Utrecht, Netherlands and London, England. The Eureka Institute for Translational Medicine is an international collaborative community of translational medicine professionals. Apollo Toronto provides a general overview of TR to interested medical/ graduate students, with the aim of establishing an international network of medical and research professionals that will expand the mandate of translational research at the respective institutions. Through discussion meetings, lectures, socials and a summer school, Apollo Toronto fosters a sense of community amongst trainees who have an interest in pursuing and promoting TR. 
Apollo Toronto's main initiative is discussion meetings, which focus broadly on how findings from research in the biomedical, clinical and health systems can be used and can be built upon to address a particular health need. These discussion meetings are followed by a debriefing session, in which members critically reflect on the knowledge gaps presented and brainstorm potential solutions [7]. In addition to organizing student-led discussions, Apollo Toronto has partnered with the University of Toronto's Translational Research Program (TRP). Apollo Toronto members are invited to attend TRP-hosted lectures and seminars. These talks are led by experts involved in various aspects of the TR pipeline, including knowledge translation, clinical trials and commercialization. Members are actively encouraged to reflect on 1) the specific roles along the TR pipeline that are of particular interest and complement their skill-sets, as well as 2) how they can develop themselves to be more effective within those roles. Moreover, Apollo Toronto members are invited to TRP social events to network with other likeminded trainees and build upon both their personal and professional identities.

In addition to its local initiatives, Apollo Toronto provides funding for two active members to attend the Eureka Institute summer school in Utrecht, Netherlands. The summer school is a one-week course jointly organized by the Eureka Institute and the University Medical Centre Utrecht. Similar to Apollo Toronto's discussion meetings, the course exposes students to the challenges of translational medicine and the inefficiencies of the current system. Through interactive lessons from leaders in academia, industry and government, the course offers students insight into how trainees can structure their research careers to address these complex issues. In addition to building upon the concepts that students learned throughout the year, the summer school gives students the unique opportunity to be taught by international TR experts and to network with academic and industry leaders. Apollo Toronto's discussion meetings and lectures provide students with a fundamental understanding of TR and the issues surrounding it. The summer school course builds on this knowledge base by challenging students to apply those skills to conceptualize new health solutions. Moreover, the course offers a unique mentorship opportunity for trainees without formalized mentorship programs at their institutions. This mentorship is essential for the success of TR trainees, since trainees do not follow a single career path and typically have long training trajectories [8].

Ultimately, the goal of these efforts is to establish an international network of trainees equipped to address the systemic issues that impede the translation of an ever- growing body of scientific literature into health solutions. As Apollo Toronto is still early in its development, it is not yet possible to measurably determine its effects on the career choices of its members. However, we recognize a growing interest in Apollo Toronto's ideas, and therefore remain optimistic about the future.

\section{Financial support}

This work was supported by funds from Toronto Notes.

\section{References}

1. Coller BS. Translational research: Forging a new cultural identity. Mt Sinai J Med. 2008;75(5):478-87.

2. Zhang Z, Chen H, Liu D. Translational research: Lessons from past research, growing up nowadays, and development goal in future. Sci China Life Sci. 2011;54(12):1085-8.

3. Begley CG, Ellis LM. Drug development: Raise standards for preclinical cancer research. Nature. 2012;483(7391):531-3.

4. Benedictus R, Miedema F, Ferguson MW. Fewer numbers, better science. Nature. 2016;538(7626):453-5.

5. Pasterkamp G, Hoefer I, Prakken B. Lost in the citation valley. Nat Biotechnol. 2016;34(10):1016-8.

6. McNutt M. The measure of research merit. Science. 2014;346(6214):1155.

7. Palis AG, Quiros PA. Adult learning principles and presentation pearls. Middle East Afr J Ophthalmol. 2014;21(2): 114-22.

8. Straus SE, Johnson MO, Marquez C, Feldman MD. Characteristics of successful and failed mentoring relationships: A qualitative study across two academic health centers. Acad Med. 2013;88(1):82-9. 